\title{
THE INFLUENCE OF GRAVITY ON STRUCTURE AND FUNCTION OF ANIMALS
}

\author{
M. D. Ross \\ Department of Anatomy and Cell Biology, University of \\ Michigan, Ann Arbor, MI 48109, U.S.A.
}

\section{ABSTRACT}

Gravity is the only environmental parameter that has remained constant during the period of evolution of living matter on Earth. Thus, it must have been a major force in shaping living things. The influence of gravitational loading on evolution of the vertebrate skeleton is well recognized, and scale effects have been studied. This paper, however, considers in addition four pivotal events in early evolution that would seem to have been significant for the later success and diversification of animal life. These are evolution of the cytoskeleton, cell motility (flagellae and cilia), gravity detecting devices (accelerometers), and biomineralization. All are functionally calcium dependent in eukaryotes and all occurred or were foreshadowed in prokaryotes. A major question is why calcium was selected as an ion of great importance to the structure and function of living matter; another is whether gravity played a role in its selection.

\section{INTRODUCTION}

Gravity is the most constant of the various environmental conditions that influenced animal evolution. It is a pervasive force that changes little from one place to another on Earth and, very likely, has remained constant during the period of evolution of living matter. Thus, it would appear certain that gravity must have had a profound influence on the evolution of life as we know it. Still, the role played by gravity in shaping living things and their responses to other environmental parameters is less often considered than is that of the atmosphere, for example, or of temperature. In this paper I shall begin by illustrating some of the obvious adaptations to gravity observed in the largest of the mammalian vertebrates and then shall look for the primary evolutionary steps that made these later advances possible. In particular, I shall consider the subject of calcium utilization and sequestering as one topic of importance in considering how gravity might have helped to shape animal morphology and function on earth.

The concept of scale effects in animals: In a series of recent papers, Pace and Smith $(1,2)$ and smith (3) have taken up an investigation of the scale effects of gravitational loading on mamals. The principle that gravity imposes a loading effect upon living things, just as it does on inanimate structures, that will strictly limit their size was first enunciated by Galileo (4) more than 300 years ago. That is, if the force of gravitational loading exceeds cohesive forces holding the material together, the structure will collapse. The force of gravitational loading can be overcome to some extent by making certain parts stronger. For example, in a vertebrate the skeletal parts supporting body mass might increase in cross sectional area. This can be observed, in fact, in limb bones of a rhinoceros or elephant which are massive in cross-sectional area to better support body mass. Moreover, in certain terrestrial species of great size where the abdominal contents as well as those of the thoracic space would be at risk due to gravitational pull as the animal moved about, the vertebrae are strengthened and the rib cage is elongated. This modification in the size of the $r i b$ cage is found in so-called "graviportal" animals (5), of which the elephant and rhinoceros are two living examples. Interestingly, the hippopotamus, which is a large amphibious mammal, lacks the graviportal rib cage and its bones are relatively less massive.

Completely aquatic forms, such as the living whales, have proportionally much less massive vertebrae and ribs than do either terrestrial or amphibious vertebrates. The vertebral column supports little or no weight, due to the neutral buoyancy of the whale. Buoyancy in the water environment permitted aquatic vertebrates to achieve the greatest mass of any known species, living or extinct. The largest of the whales, the blue whale, may weigh as much as 150 tons and be 150 feet long. In the whales, streamlining of the body for water habitation further rasulted in shortening of the brain case and the neck, with partial to 
complete fusion of the cervical (neck) vertebrae. The whale uses its tail flukes, which lack skeletal support, for propulsion through the water. Its hind limbs have disappeared and its forelimbs, used largely for stabilizing, are much shortened and paddle-like (5). In contrast, seals and walruses which spend great amounts of time in the water but return to land for breeding purposes have a well developed vertebral column and have retained appendages that have sturdy skeletal parts. The limbs are paddle-like and are used in swimming but also help support body weight during locomotion on land.

The skeletal modifications just described illustrate some of the structural changes that have evolved to accommodate support of large mammalian body masses under a variety of environmental conditions. Small mammals do not face the same problems as large ones. Pace anc Smith (1) have computed the proportion of body mass given over to skeleton to be about 58 for a 5 gram shrew, 358 for a $12,000 \mathrm{~kg}$ elephant, and only about 158 for whales (even for the blue species). Clearly, there is a relationship between gravitational loading and body size within the vertebrate series, as originally predicted by Galileo many years ago, with a water habitat distinctly advantageous. Loading also results in changes in the thickness of supporting skeletal parts, and exaggeration of ridges and protuberances where muscles attach. The relative density of the bone in different species does not always appear to be related to loading.

It is obvious, however, that adequate support of body mass is not the only critical factor in determining limitation of body size for multicellular organisms evolving in a gravitational field. The circulatory system must be capable of delivering blood to the various body parts, and of bringing waste products from them to the appropriate organs for removal. Blood delivered to the extremities, including the tail, must be brought back from them against the force of gravity. To accomplish this, specific force of contraction of the heart, appropriate elasticity of the arterial blood vessel walls, and a system of one-way valves in the venous system are among the specializations required to counteract the tendency of blood to pool in dependent body parts. Thus, there would appear to be limitations on body size dictated by the need for effective blood circulation. The limitations likely differ whether one is considering poikilotherms or homeotherms, and most certainly differ between aquatic and terrestrial forms. Here, one might consider the success in the past of huge reptiles, the dinosaurs, for poikilothermic terrestrial animals; and of the mastadons, another extinct group, for terrestrial homeothermic mamals.

Among living mamnals, the giraffe presents its own peculiar problems of blood pressure control to the head region during grazing and normal posture, with the head upright upon its greatly elongated neck; and during drinking, when the head is brought down to the water in a pond. Perhaps some grasp of the enormity of the problem for the giraffe can be obtained by considering that some humans have difficulty in regulating blood pressure to the head upon rising from a recumbant to an upright position. Blood pressure is regulated in part by baroreceptors (pressure receptors) in the major blood vessels supplying the head, the common carotid arteries, which are innervated by the ninth cranial nerve. Failure of the activated neural circuit to reflexly adjust blood pressure upon rising results in blackout due to lack of sufficient blood to the brain; this is called orthostatic intolerance. If humans with their relatively short necks have a need for exquisite neural circuitry to maintain the blood supply to the brain during changes of position of the head in a gravitational field, how much more exquisite is the requirement in the giraffe!

In concert with skeletal and cardiovascular requirements in a gravitational field are those of the muscuiar system, since it is the muscles that actually move the skeletal parts. Moreover, it is the cardiovascular system that delivers oxygenated blood and removes waste products incurred through muscular activity. Specific muscles work to maintain the position of the body appropriate for the species against the forces of gravity. These are the antigravity muscles particularly of the extremities and neck, but also along the vertebral column in most quadrupeds. As body mass increases, muscle mass must also increase but the relationship would be expected to be different for aquatic and terrestrial forms. Increased muscle mass means more weight and increased metabolic requirements. But, as already indicated under the discussion of the mammalian skeletal system, more mass can be maintained with less expenditure of energy in an aquatic environment where body mass is largely supported by the water.

Another kind of limitation might be imposed by the nervous system which, in the end, directs the activity of the musculoskeletal system. Increased length of the spinal cord, or of the distance from the cord to the nerve terminals in distal skin and musculature, would place additional burdens upon the intrinsic transport capacities of the nerve celis (neurons). These cells have extensions, called axons, that pass from the cell body toward other neurons with which they communicate. Some axons extend from a brain center to the distal part of the spinal cord, a distance of up to 60 feet or more in some dinosauxs and of over 100 feet in the largest of the living whales. proteins and organelles of axons and their terminals arise in the cell body, the trophic center of the neuron, and are moved down the axons by mechanisms of fast and slow transport, respectively. Does gravity impose a limit on the distance over which transport can occur in neurons? There is no 
hint of an answer in the literature.

It is interesting, however, that other body organ systems do show apparent scale effects, at least among mammalian vertebrates. There is approximately a 1.055 power relationship between muscle and total body mass in mamnals while the viscera scale at about 0.871 power (1). Blood volume scales as a 0.987 power (6) of total body mass. There is a further scale effect between metabolic heat production rate and body mass. This figure was determined to be a $3 / 4$ power relationship (7) for terrestrial mammals, although a $2 / 3$ power scale effect had been expected based upon surface area changes with increasing size. Total metabolic rate, however, decreases with increasing size with about -0.25 scaling (1). This means that the metabolic intensity (metabolic rate per unit of body mass) is greater in a small mamal like the mouse than in a much larger one like the elephant. It is unknown whether scaling effects are entirely due to the influence of gravitational loading, but there is an apparent relationship in many instances. It is interesting to note, noreover, that scale effects are not equivalent for the various systems in mamals. It would be intriguing to know whether one or another of them is the rate limiting factor. In this context, it is important to note that neural structures have not been included thus far in studies of scale effects, nor has a comparison been made between poikilothermic and homeothermic vertebrates. Studies of differences between aquatic and terrestrial vertebrates are also scarce but could prove to be especially illuminating.

If scaling effects closely reflect limitations imposed by gravitational loading then one would expect differences to occur under either weightlessness or increased loading. As Smith (3) has pointed out in a recent article, scaling effects do seem to represent a continuum in those cases where measurements are available. Red cell mass increased in chronically accelerated animals (8) and was decreased in astronauts post-flight (9). Bone mineralization was arrested in rats exposed to weightlessness (10); and loss of calcium from the body as well as thinning of the os calcis was reported in astronauts (11, 12). Loss of muscle mass and of fluid occurred in astronauts, and hormonal imbalances were present (13, 14). Thus, it would seem that man and other animals are finely tuned physiologically to Earth's gravitational field.

But what were the evolutionary "leaps" that made possible the diversity of animal life that has existed on planet Earth, and culminated in intelligent beings, within this unique environmental condition? Is life as we know it largely a consequence of Earth's gravitational field? Although the notion seems outrageous at first glance, let us examine it by considering some facets of animal evolutionary history.

\section{EARLY EVOLUTION OF IIFE}

Initial organisms evolved more than 3.5 billion years ago under anaerobic conditions. There was little free oxygen in the atmosphere and no ozone layer to protect Earth from ultraviolet irradiation. Laboratory experiments designed to mimic the primitive, violent environment have shown that small molecules of all the basic building blocks of organic macromolecules can be formed from mixtures of gasses containing carbon, nitrogen and hydrogen heated with water and subjected to electrical discharge or ultraviolet irradiation. These test-tube reactions are greatly facilitated by organic catalysts (enzymes), and primitive enzymes and small proteins may have been generated simultaneously in Nature. Once sufficient organic molecules were around, it is not difficult to imagine that some of them would have been trapped within vesicles that included sufficient organic machinery to conform to living cells. Cell membranes are constructed of phospholipids and proteins; artificial vesicular membranes are made quite simply in a test tube by mixing phospholipids and water. It should be noted that calcium helps stabilize both artificial (15) and bacterial plasma membranes (16).

The first living cells lacked a nucleus and probably would have corresponded to what we recognize today as prokaryotes $(17,18,19)$. Some of these primitive organisms changed forever the course of evolution by carrying out photosynthesis. Once cells began to capture electrons from water, oxygen, a by-product of photosynthesis, accumulated in the atmosphere. Once oxygen was available, both aerobic and anaerobic metabolism could take place. The next major advance was the evolution of the eukaryotic (nucleated) cell and then of the Protista, which includes the protozoans, the early animals from which the invertebrates and the vertebrates of the Animal Kingdom sprang.

\section{GRAVITY PERCEPTION AND THE EVOLUTION OF ANIMAL LIFE}

As we have already discussed, gravity is the only environmental parameter that has remained constant since life began. It is obvious, then, that if it became advantageous for an organism, whether unicellular or multicellular, to orient itself in space for purposes such as food-seeking or escape, gravity was the most useful parameter to employ. For gravity to prove useful in orientation, however, it first and foremost had to represent an environmental perturbation to evolving living organisms. 
As Adams and Rinne (20) have emphasized, great genetic diversity exists in any given population, with only a small portion of the hereditary material needed to code for the proteins actually produced. They point out further that about 938 of the enzyme activities listed in tables published by the International Enzyme commission exist in both prokaryotes and eukaryotes. What accounts, then, for the enormous diversity of living organisms? Adams and Rinne (20) and others (21) have suggested that environmental conditions interact with the cytoplasm to affect gene expression. An altered genome which responded to a particular environmental condition might be hereditary, producing new phenotypes.

According to this viewpoint, for gravity to have become a force in evolution it had to have become an important environmental condition to which a gene regulatory response became necessary. For example, achievement of greater mass by a primitive organism meant the possibility of sinking to the depths of the sea, possibly out of the range of necessary nutrients, light or tolerable pressures. At this point, gravity became a perturbation that could lead to cell death and, unless there existed sufficient diversity to provide for an appropriate response, further evolution would have been inhibited.

With this illustration in mind, what might the pivotal evolutionary advancements have been that represented direct interactions between the force of gravity and cells which helped shape all animal life on Earth? In my opinion these would include evolution of 1) cytoskeleton; 2) cell motility (flagellae and cilia); 3) gravity- and other accelerationsensing devices; and 4) biomineralization. An indirect effect of gravity is through pressure, whether atmospheric, geologic, or hydrostatic, so that the evolution of baroreceptors is also related to gravity. Other evolutionary consequences of the four advances Iisted would seem to be organization of animal structure with dorsoventral and anteroposterior directionalities; and basal metabolic rates for animals that included the expenditure of energy necessary to overcome gravity.

It will be noted that none of these is molecular in nature. This is not to say that gravity had no effect upon early evolution of macromolecules and cell membranes. Rather, their omission but reflects the present state of our ignorance concerning the threshold for gravitational influence. It will be noted further that all of these central evolutionary advances had already occurred in eukaryotes and most are already present in prokaryotes. Nearly all of them involve calcium as a modulator. Each is considered briefly below.

Cytoskeleton: The gathering of macromolecules into a bag of seawater to form the first cell immediately meant that the macromolecules, if heavier than the cytosol, would segregate into strata by weight. Evolution of intracellular vacuoles, chromosomes, a nucleus and other organelles compounded this problem. It is not surprising, therefore, that cytoskeletal support evolved very early. Actin and microtubules, which are cytoskeletal components in mammalian cells, have survived virtually unchanged in all eukaryotes, where they are under calcium regulation. It is not far-fetched to say that the evolution of eukaryotes and of cell aggregates required the evolution of a cytoskeleton, and that this was dictated by the presence of a gravitational field.

Because cytoskeletal components are attached to the plasma membrane, inertial shifts in the locations of intracellular contents supported by them would occur with movement in a gravitational field. These in turn, could stress the actin filaments and trigger changes in membrane conductance for ions at the cell surface to regulate the response. However, the limits of detection by a cytoskeletal system are currently unknown. Are they just above effects of thermal noise for example? This question was discussed by Tsien (22), but the answer remains unknown (see related discussion under why calcium?, below).

Actin-like proteins have been discovered in certain bacteria (Escherichia coli, 23) where they are proposed to be ATP-dependent and to play a role in cytotonus. That is, the contractile proteins may be used to regulate $\mathrm{Na}^{+} / \mathrm{K}^{+}$ion exchange at the cell membrane to maintain cell water optimal. Thus, the evolution of actin may have been a primitive response linked to regulation of cell water content. It is of interest to note that all cells maintain a high internal $\mathrm{K}^{+}$and low internal $\mathrm{Na}^{+}$compared to the concentrations of these ions extracellularly. It has been proposed that utilization of $\mathrm{K}$ rather than $\mathrm{Na}^{+}$for water regulation by cells is related to the size of the hydrated radius of the ions (the hydrated radius of $\mathrm{K}^{+}$ions being the smaller) and the small amount of water molecules avajlable in microorganisms (23). Success of the primitive microorganisms in concentrating $\mathrm{K}^{\dagger}$ imprinted forever the further course of cellular evolution on Earth. Whether or not this cytotonusrelated response represents a gravitational influence on the evolution of cellular ion transport systems has not been tested in the space environment.

The evolution of contractile proteins had enormous consequences for the later evolution of animal life. Actin and myosin became arranged in a specific, almost quasi-crystalline way in muscle cells, permitting evolution of the muscular system that is important to motility in metazoans. But the organization of actin and myosin in other kinds of cells is less rigid and actin was thus able to participate in a number of functions of evolutionary importance. Actin and myosin figure in cell motility, cell shape, exocytosis and endocytosis, 
to name but a few functions (see 24, for review). Microtubules also contribute to cytoskeletal support but function as well in the transport of organelles intracellularly, in spindle formation and in chromosome separation during cell division. Calcium modulates all these functions.

Cell motility, the evolution of flagellae and cilia: Cells of a weight equivalent to that of the water they displace will float and tumble about. They are at the mercy of the motion of the fluid in which they find themselves. Those heavier than the displaced water will sink. one way of overcoming tumbling or sinking is to move. The evolution of flagellae allowed more simple microorganisms to control their position in gravitational space and in the chemical environment. In bacteria, flagellar motility is used in chemotaxis. Bacterial flagellae (unlike flagellae and cilia of protists and higher animals) lack microtubules, which are sensitive to intracellular levels of free calcium. Nevertheless, in certain bacteria (B. subtilis) increased levels.of $\mathrm{Ca}^{2+}$ were shown to direct flagellar rotation to the clockwise direction, which favors tumbling (25). The nature of the "switch" that controls the direction of flagellar rotation, and thus swimming or tumbling, is unknown. It appears, however, that, in the absence of $\mathrm{Ca}^{2+}, \mathrm{Mg}^{2+}$ binds to the switch and induces counterclockwise rotation and a swimming motion. In the absence of either ion, the switch stays in the tumbling mode. The findings would suggest that control of ciliary motion by slight changes in levels of intracellular free calcium, through an organic, intermediary molecule (a protein?) is very old.

Ciliated cells are common in the respiratory and reproductive tracts of the most advanced of animal life where they are used to propel materials against the force of gravity. Spermatazoa use a flagelium to swim toward eggs, permitting a variety of reproductive environments for egg fertilization.

Gravity and Baro- Receptors: Motion of large unicellular and of multicellular organisms can be better controlled in a gravitational field if there are specific sensors for gravity and translational linear and angular accelerations (accelerometers). All that is required for gravity sensing is a "test mass", material heavier than the surrounding milieu, and some mechanism for recognizing inertial drag or field potential changes as the mass responds to gravity. In mobile animals, however, inertial forces will act on this same device during body accelerations so that it might also be used as an accelerometer to detect the direction and rate of movement. This information would be useful to organisms attacking a food source, or seeking escape.

The first example of a structure that corresponds to a primitive statocyst-accelerometer occurs in protozoa (Protista, the first animals) in Infusorians $(26,27)$. The drawings of Luxodes and Holotrichia in Vinnikov (28) show the presence of a "concretion vacuole" which contains a number of mineral particles of unknown composition. The vacuole itself is connected by means of "loading fibrils" to the cell membrane which is covered with cilia. Assumedly, movement of the particles in a gravitational field loads or unloads the fibers. This, in turn, results in ciliary responses to move the animal to a new location. There is, apparently, no direct proof that the "concretion vacuole" is a gravireceptor, nor is the mechanism responsible for ciliary motion known. It would seem that Infusoria would be worthy of new study to learn the composition of the particles, the nature of the loading fibers (are they actin filaments?), and whether the response is mediated by Ca . Regardless, the device may represent an evolutionary step towards sensory accelerometers characteristic of mobile, multicellular animals.

Neither the use of vacuoles nor of biomineralized particles in seeking a specific water level as a habitat is confined to the unicellular animals containing statocyst-like vesicles. Paramecia have digestive vacuoles which may act as statocysts, as shown by experiments involving the ingestion of iron and the use of a magnet to imitate the loading force of gravity $(29,30)$. Cytoskeletal elements assumedly play a role in the response. Some protozoans use gas vacuoles for buoyancy. Protozoan vacuoles are foreshadowed by the "gas vacuoles" of certain bacteria which are thought to function as baroreceptors rather than as gravity receptors per se. Here, the role of gravity is indirect, but real, as it is related to gravitational loading on water of rivers, lakes and the sea which results in increased pressure with depth. It is of interest that pressure effects are in the direction of disassociation of "polymeric aggregates" such as microtubules and multimeric enzymes (31), and of denaturation of proteins, in protozoans as well as in the cells of more complex animals. Does gravitational loading have similar effects?

The presence of mineral particles in protozoans has a counterpart in some bacteria which attract metallic ions to macromolecules at the surface of their cell coats. In some species, captured iron is internalized and biomineralized into small magnetite $\left(\mathrm{Fe}_{3} \mathrm{O}_{4}\right.$ ) crystals (32). The magnetic crystals are used by the bacteria to guide them along geomagnetic lines to specific levels in the sediments, to escape oxygen at the surface $(32,33,34,35)$. This would correspond to negative chemotaxis. Because the bacteria move to specific depths in the sediments, however, it is possible that a gravitropic component coexists. In other species of bacteria the iron is not internalized but is precipitated at the cell surface 
as inorganic ferric-oxide in reguiar, hexagonal array (unidentified species of Lepotryx, 36). In still another species of cyanobacteria, successive layers of needle-shaped calcite crystals are deposited on external cell surfaces. The crystals in the alternate layers are orientec perpendicular to one another. Acidic demineralization of these crystals has demonstrated that they possess an organic framework (37). This crystallization may correspond to an early example of organic matrix mediated biomineralization (38) of a calcium carbonate polymorph, later utilized so effectively in shell formation by invertebrates (see below).

Since inclusion of magnetite or the addition of a mineral to cell coat surfaces would have greatly increased the mass of the microorganisms just discussed, the question arises whether similar crystalline deposits were among the first attempts of living cells to construct "test masses" useful in detecting the direction of gravity?

A complete review of the evolution of gravity receptors of higher animals is beyond the scope of this paper. With invertebrates, however, gravity receptors began to take on an organization that was maintained throughout animal evolution and they became connected to neural structures that gained more and more dominance over motor responses. The basic plan of most invertebrate and all vertebrate gravity receptors is the presence of one or more mineralized particles (a "test mass", 28) within a fluid-filled compartment; a close, physical relationship of hair celis to the extracellular test mass; and a neural innervation of the sensory hair cells. Beginning with cephalopod molluscs, such as the octopus, there are maculae and cristae analogous to those of vertebrates, which serve in detection of linear and angular accelerations respectively; and receptor cells are distinct from the nerve fibers that conduct acceleratory information centrally (28).

The trends established in the invertebrates helped make possible the evolution of land vertebrates and of appendages for locomotion. That is, gravity and acceleratory information became an important sensory input to assist the neuro-musculo-skeletal system in reflexly maintaining body posture and equilibrium in a gravitational field, whether the animal was at rest or in motion. Orientation in a gravitational field had side effects in cellular and metazoan organization. It favored animals in which cell or body parts were functionally organized relative to gravity to achieve forward motion; that is, dorsoventral and anteroposterior organization which ultimately resulted in multicellular animals with heads and tails and with bilateral symetry.

Biomineralization: An important evolutionary step toward biomineralization was made by mitochondria, which captured calcium ions at their surfaces, internalized the ions electrophoretically and then precipitated them as amorphous deposits. The process is largely energy dependent (See 39).

It has been hypothesized that mitochondria, present only in eukaryotes, were aerobic microorganisms that were incorporated symbiotically into anaerobic cells, since they alone carry on the respiratory activities of the cell. Once incorporated, their ca ${ }^{2+}$ sequestering capacity could be used to remove excess calcium from the cytosol for precipitation internally as a salt. This would provide a mechanism for regulating intracellular $\mathrm{Ca}^{2+}$ and for maintaining an essential store of the ions against time of need, permitting the use of calcium in the modulation of a variety of cell functions. It would seem likely that ca ${ }^{2+}$ modulation of some cell functions should have already been established, to make the symbiotic relationship of mutual benefit to both cells, although evidence from modern prokaryotes is practically non-existent (see section on motility, above).

Mitochondria can accumulate substantial amounts of calcium phosphate. The quantity of calcium alone can amount to more than a third of their dry weight (40). A symbiotic relationship, "floating" inside another cell, may have been a clever alternative to sinking into an abyss! Coincidentally, the inclusion of mitochondria with their outstanding ability in concentrating calcium may have been a vital evolutionary step that made biomineralization possible on a grand scale. Mitochondrial precipitation of calcium and phosphate ions as amorphous calcium phosphate, or possibly as ultramicrocrystalline tricalcium phosphate (41), has been hypothesized to be the first step in biomineralization of the vertebrate skeleton (42). According to this hypothesis, the amorphous mineral deposit is secondarily moved to an extracellular compartment where it is reconstituted as crystalline bone mineral. Because mitochondria can, in some situations, deposit calcium carbonate rather than the phosphate $(43,41)$, it is possible that mitochondria participate in biomineralization of shells and inner ear crystalline materials which consist of polymorphs of calcium carbonate. They may also be of importance in biomineralization of silicon (41). Since most exo- and endoskeletons are comprised of calcarous or silicaeous materials (see charts in 37), the attention paid to a possible role for mitachondria in biomineralization seems warranted.

As already discussed, prokaryotes are very successful at precipitating crystalline materials outside their cell walls and intracellulary, both biologically induced and organic matrix-mediated (38) processes. Once the ability to biomineralize appeared in living things, its preservation cepended upon the adaptability of the oxganism endowed with the 
gravi-sensitive, additional mass. It had to be successful at feeding, escaping predators, and reproducing in its new niche. It also had to control the mineralization process lest it build a coffin instead of a usable shell. Control was accomplished on a more global scale by hormones (44) and locally by inhibitors, with the use of feedback systems that utilized circulatory and nervous systems in higher animals. Thus, there were many corollary evolutionary demands when biomineralization became prominent. Which mineral was deposited may have depended more on the availability of raw materials and upon the inhibitors present (for example, phosphate or carbonate, see 45) than upon any gravitational advantage. The actual shape taken by a particular shell or bone is genetically determined but influenced by many environmental factors, one of which is gravitational loading $(10,46)$.

The ability to biomineralize may have evolved separately in many eukaryotes, many times in evolution. It is, therefore, amazing that the organic substrate that directs the growth of a specific crystalline material, orders the crystallites in highly specific ways, and limits their dimensions, should be so similar among living animals (see 47 for excellent discussion). To cite but one specific example, calcite particles of the vertebrate gravity receptors contain organic material that is high in acidic and low in basic amino acids (48), and this relationship is present in calcite-containing invertebrate shells (49). Indeed, acidic proteins are commonly found in organic matrices of all examples of matrix-mediated biomineralized materials analyzed to date (47). The commonality of "framework" macromolecules (which differ greatly among species) and of acidic proteins (which remain more similar) in such materials has led weiner et al. (47) to speculate that the ability to biomineralize may have evolved in the Precambrian period, from some common ancestor; and that the trend from calcium phosphate biomineralization in the late precambrian period to calcite and aragonite in later periods might reflect increasing complexity of the organic template.

Aside from its importance in the evolution of gravity receptors, invertebrate shells and vertebrate skeletons, the ability to biomineralize had further evolutionary significance. Successful internalization, processing and secretion (or exeretion) of calcium by primitive cells foreshadowed the later evolution of hard shelled eggs for survival of embryos on land; and the evolution of mamuls, whose milk-producing glands proved useful in nourishing offspring that were sometimes born at a fetus-like stage of development.

\section{WHY CALCIUM?}

The functional advantage of nipping off a bit of the sea and thereby creating a new milieu within which molecular interactions could proceed could only be maintained if the cell became organized to transport ions and nutrients to counter diffusion gradients. Diffusion across freely permeable membranes would soon bring the internal and external cellular environments to equivalency which is entropy, or cell death. It is humbling to realize that primitive microorganisms solved this problem through the evolution of membrane transport systems and metabolic reactions that are not very different from those used in cells of our own bodies. $\mathrm{Na} / \mathrm{K}^{+}$exchange has already been mentioned in the discussion below. Another important ion that is strictly regulated at low concentrations intracellularly and became an important trigger for numerous cell functions is calcium.

The internal calcium copcentration of all, or nearly all, living cells is maintajned within the narrow range of $10^{-7}$ to $10^{-8} \mathrm{M}$ compared to an external concentration of $10^{-3} \mathrm{M}(50,51)$. To achieve low internal calcium, bacteria, the moşt primitive of living organisms, use a variety of transport systems. These include 1$) \mathrm{Ca}{ }^{2+} / \mathrm{H}^{+}$antiport, as in Escherichia coli; 2) $\mathrm{Ca}^{27} / \mathrm{Na}^{+}$antiport, as in Halobacterium halbium; and 3) $\mathrm{Ca}$ /ATPase transport in streptococcus faecium (52). These same methods of calcium ion transport are used in invertebrate and vertebrate cells. Calcium-sodium exchange is the dominant kjind of transport used in heart muscle, squid neurons and renal epithelium (53), while Ca /ATPase is found along the

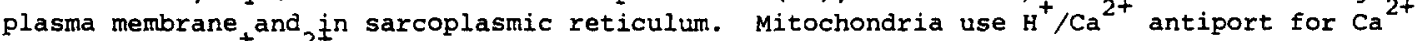
uptake and a $\mathrm{Na}^{+} / \mathrm{Ca}^{27}$ exchange for calcium efflux (54).

The evolution of ion transport mechanisms to regulate intracellular concentrations of ions simultaneously provided electrical gradients across cell membranes that would prove useful as a source of energy. If modern prokaryotes are any indication, however, primitive prokayyotes did not use calcium extensively as an intracellular messenger (see discussion of $\mathrm{Ca}^{27}$ utilization by bacteria in 55). Control of direction of flagellar rotation (25) and calcium accumulation during sporulation (55) would appear to be important exceptions. While the link to eukaryotic utilization of calcium in so many biologic functions is thus lost to us, by the time animals and plants appeared on the face of the Earth the basic machinery to regulate intracellular ions, to modulate $\mathrm{Ca}^{2+}$ for use as a messenger in cell activities and to produce calcarous biomineralized materials already existed. The fundamental questions in evolution are why calcium ions were selected out for their many vital functions in living organisms, and whether gravity played a role. 
of alternative answers, among which are the following. 1) Extrusion of Ca ${ }^{2+}$ occurred first; following this, the cell began to utilize the calcium ion gradient in information transfer. 2) Calcium extrusion protected against internal precipitation of phosphate, leaving phosphate for yse as the "basic energy currency" of cells. 3) $\mathrm{Ca}^{2+}$ pumps may have evolved to protect $\mathrm{Mg}^{2+}$ dependent enzyme systems. Kretsinger has also discussed the notion that the original ion pumps may have been unspecific for sodium and calcium ions, both of which were pumped outward. As he and others have noted, the ionic radii of sodium and calcium are very similar, $0.85 \mathrm{~A}$ and $0.99 \mathrm{~A}$ respectively. Thus, calcium extrusion may have been coincidental with sodium extrusion which, as noted above, possibly was related to cytotonus. Finally, Kretsinger (62) presented the hypothesis that calcium modulated proteins contain $\mathrm{EF}$ hands. This refers to the particular configuration of the proteins that provides in each case a helix, $\mathrm{Ca}^{2+}$ binding loop, and another hejix (63). He has raised the interesting questions whether the amino acid sequence of $\mathrm{Ca}^{2+}$-ATPase indicates homology with $\mathrm{Na}^{+}, \mathrm{K}^{+}$, ATP-ase or with the family of calcium binding proteins that have EF hands? And, whether prokaryote $\mathrm{Ca}^{2+}$-ATPase is homologous to that of eukayyotes? These are important considerations because the calcium-binding portion of the $\mathrm{Ca}^{27}$ modulated proteins was highly conserved during evolution (see also 64). Calmodulin, for example, is an intracellular, calcium modulated protein apparently ubiquitous in eukaryotic cells; but all efforts to demonstrate it, or another such protein with EF hands, have proven fruitless in the case of prokaryotes (see discussion in 65). Did these proteins evolve from substances used in ion transport at the cell membrane of primitive microorganisms?

Lowenstam and Margulis (61) favor the second of Kretsinger's proposals listed above; but it should be noted that in mitochondria, at least, uptake of a permeant anion (like phosphate) is obligatory if calcium uptake is to go forward (see discussion in 55). Lowenstam and Margulis have emphasized further that calcium modulation proceeded skeletalization.

williams has taken a somewhat different approach in dealing with the issue, why calcium? He has considered particularly the physico-chemical properties of calcium and its protein ligands. Briefly, Williams has stressed that calcium is unique among the ions that might be considered as competitors at binding sites, such as magnesium and sodium, in that $\mathrm{Ca}^{2+}$ has a coordination number of 7 or 8 , and the coordination geometry is irregular in bond angle and length (58). In contrast, for example, $\mathrm{Mg}^{2+}$ maintains 6 coordination in a closely regular octahedron. Thus, the functions of the two ions are quite different in biological systems. Magnesium because of its regularity, is not well suited to bind to the irregular geometries of coordination sites in proteins, polysaccharides, or complexes of carbohydrate and protein that are generally used to bind calcium in biology. Moreover, as an ion binds to a ligand, it changes the configuration of the ligand. Calcium, because of its "looser" requirements for coordination can still bind to the organic molecules, or find new binding sites, as the molecules change their configurations. Moreover, different configurations of the ligand could have differing effects functionally within a cell greatly amplifying the potential interactions of a single ligand and its metallic ion $\left(\mathrm{Ca}^{2+}\right)$. Williams also deals with the thermodynamics of calcium binding, in which the hydrated radius of the metal ions is important, and with the effects of other ions in the medium on binding of any ion to a ligand. If this line of reasoning is followed, then it would seem that evolution of calcium utilization in so many functions of animal cells is an end product of the physicochemical nature of the available inorganic elements on one hand, and of organic molecules on the other.

While the initial phases of calcium utilization by organic molecules and later by cells may then be considered to be unrelated to gravitational influence, we may still ask, was it? Gravity was responsible for capturing a specific atmosphere, and remains responsible for the cyclic interactions between living and non-living things (see Gaia hypothesis, 66). The addition of one to several calcium ions to a molecule changes the mass and weight of that molecule.

Pollard (67) concluded on theoretical grounds that small masses, such as cells below about $10 \mu \mathrm{m}$ in diameter (which would include many bacteria), would not be influenced by gravity because gravitational forces would be overcome by more rapid Brownian movement. However, Nace (68) has calculated that rotational effects of gravity (torque) will be exerted on free cells below this dimension, using as one example a sarcoma cell 6.4jm long. He and others have postulated that energy is required for positional homeostasis in a gravitational field. Support for this concept comes from the findings of Montgomery et al. (69), who reported a 588 decrease in glucose utilization in a space-flown tissue culture of human lung cells compared to Earth-bound controls. Ultrastructural organization in the bacterium Proteus vulgaris differed in space-flown cultures compared to controls on Earth, when growth concitions were optimal. Changes in growth patterns were identical for both cultures when conditions were purposely varied from optimal, indicating a specific role for gravity in the ultrastructural organization of these bacteria.

These few examples should indicate that we are still a long way from understanding the role of gravity in shaping early macromolecules and primitive living cells, or from knowing the size of the critical mass necessary for gravity to have an effect. The secret to 
understanding the evolution of animal forms of life, however, is inextricably interlocked with understanding the influences that shaped living things from the very beginning. Given the elements available and the atmosphere and violent environment at the time, and the constancy of gravity during the entire course of evolution, we might ask if life could have evolved in any other way than it did on Earth? There are corollary questions to pose. One is, in a weightless environment, will animals evolve to forms not currently present on Earth? And, if unique elements exist under different but appropriate environmental conditions to spawn "living" structures in some far distant galaxy, will we recognize them as living when (and if) we find them?

\section{ACKNOWLEDGEMENTS}

Support by NASA, contract \#NAS2-10535 and Grant \#NSG-9047, is gratefully acknowledged.

\section{REFERENCES}

1. N. Pace and A.H. Smith, The Physiologist 24, S-37 (1981)

2. N. Pace and A.H. Smith, The Physiologist 26, S-125 (1983)

3. A.H. Smith, The Physiologist $25,5-47$ (1983)

4. G. Galilei, Dialogues Concerning Two New Sciences, 1638, (English Trans. S. Drake, Wisconsin Press, Madison, 1974)

5. J.z. Young, The Life of Vertebrates, Oxford University Press, London, 1950

6. S. Brody, Bioenergetics and Growth, Reinhold, New York, 1941

7. M. Kleiber, in: Energy Metabolism of Farm Animals, eds. K.I. Blaxter, J. Kielanowski and G. Thorbek, Oriel, Newcastle upon Thyne, 1969, p. 505

8. R.R. Burton and A.H. Smith, Space Life Sci. 1, 503 (1969)

9. S.I. Kimzey, P.C. Johnson, S.E. Ritzman and C.E. Mengel, Av. Space. Envt. Med. 47, 383 (1976)

10. E.R. Morey and D.J. Baylink, Science 201, 1138 (1978)

11. P.B. Mack, P.A. LaChance, G.P. Vose and F.B. Vogt, J. Roent., Rad. Ther. Nuc. Med. 3, 503 (1967)

12. P.C. Rambaut and R.S. Johnston, Acta Astronaut. 6, 1113 (1979)

13. C.S. Leach, Acta Astronaut. 6, 1123 (1979)

14. H. Sandler, The Physiologist 22, S-19 (1979)

15. T. Ito and S.-I. Ohnishi, Biochim. Biophys. Acta 352, 29 (1974)

16. M. Ehrstrom, L.E.G. Eriksson, J. Israelachvili and A. Ehrenberg, Biochem. Biophys Res. Commun. 55, 396 (1973)

17. H. Morowitz, Progress in Theoretical Biology 1, 35 (1967)

18. L. Margulis, Biosystems, 12, 105 (1980)

19. L. Margulis and J. Stoltz, in: Biomineralization and Biological Metal Accumulation, eds. P. Westbroek and E.W. DeJong, D. Reidel, Dordrecht, 1983, p. 27

20. C. Adams and R.W. Rinne, International Review of Cytology 79, 305 (1982)

21. M.W. Ho and P.T. Saunders, J. Theoret. Biol. 78, 305 (1982)

22. R.Y. Tsien, in: The Regulatory Functions of Calcium and the Potential Role of Calcium in Mediating Gravitational Responses in Cells and Tissues, ed. S. Roux, NASA, Washington, D.C., 1983, p. 279

23. L. Minkoff and R. Damadian, J. Bacteriol. 125, 353 (1976)

24. M. Schliwa, Cell 25, 587 (1981)

25. G.w. Ordal, Nature 270, 66 (1977)

26. R. Penard, 1922, quoted by Ya. A. Vinnikov, 1974, Minerva Otorhinolaringol. 24, 1 (1974)

27. V.A. Dogiel, Arch. Protistenkunde 58, 319 (1929)

28. Ya. A. Vinnikov, Minerva Otorhinolaringol. 24, 1 (1974)

29. O. Koehler, Arch. Protistenkunde 45, 37 (1922)

30. H. Merton, Arch. Protistenkunde 85,33 (1935)

31. R.E. Marquis and P. Matsumura, in: Microbial Life in Extreme Environments, ed. D.J. Kushner, Academic Press, New York, 1978, p. 105

32. R.P. Blakemore, Science 190, 377 (1975)

33. R.P. Blakemore, A. Rev. Microbiol. 36, 217 (1982)

34. R.P. Blakemore and R.B. Frankel, Scient. Am. 245, 58 (1981)

35. R.B. Frankel and R.P. Blakemore, Phil. Trans. R. Soc. Lond. B. 304, 567 (1984)

36. D.E. Caldwell and S.J. Caldwell, Geomicrobiol. J. 2, 39 (1980)

37. H.A. Lowenstam and $\mathrm{S}$. Weiner, in: Biomineralization and Biological Metal Accumulation, eds. P. Westbroek and E.W. DeJong, D. Reidel, Dordrecht, 1983, P. 191

38. H.A. Lowenstam, Science 211, 1126 (1981)

39. E. Carafoli and M. Crompton, in: Calcium in Biological Systems, ed. C.J. Duncan, Cambridge University Press, Cambridge, 1976, p. 89

40. F.D. Vasington and J.V. Murphy, J. Biol. Chem. 237, 2670 (1962)

41. A.L. Lehninger, in: Biomineralization and Biological Metal Accumulation, eds. P. Westbroek and E.W. DeJong, D. Reidel, Dordrecht, 1983, p. 107

42. A.L. Lehninger, Biochem. J. 119, 129 (1970)

43. J.A. Elder and A.L. Lehninger, Biochemistry 12, 976 (1973) 
44. J. Joose, in: Biomineralization and Biological Metal Accumulation, eds. P. Westbroek and E.W. DeJong, D. Reidel, Dordrecht, 1983, p. 133

45. P.J. Cook and J.H. Shergold, Nature 308, 231 (1984)

46. J. Spector, R.T. Turner, E. Morey-Holton, D.J. Baylink and N.H. Bell, The Physiologist 26, $S-110$ (1983)

47. S. Weiner, W. Traub and H.A. Lowenstam, in: Biomineralization and Biological Metal Accumulation, ed5. P. Westbroek and E.W. DeJong, D. Reidel, Dordrecht, 1983, p.205

48. M.D. Ross and K.G. Pote, Phil. Trans. R. Soc. Lond. 304, 445 (1983)

49. V.R. Meenakshi, P.E. Hare and K.M. Wilbur, Comp. Biochem. Physiol. 40B, 1037 (1971)

50. R.H. Kretsinger, in: Metal-Ligand Interactions in Organic Chemistry and Biochemistry, Part 2, eds. B. Pullman and N. Goldblum, D. Reidel, Dordrecht, 1977a, p. 257

51. R.H. Kretsinger, in: Calcium Binding Proteins and Calcium Function, eds. R.H. Wasserman R.A. Corradino, E. Carafoli, R.H. Kretsinger, D.H. Maclennan and F.L. Siegel, Elsevier North-Holland, New York, 1977b, p. 63.

52. J. Burkler and M. Solioz, in: Transport ATPases, eds. E. Carafoli and A. Scarpa, New York Academy of Sciences, New York, 1982, p. 422

53. M.P. Blaustein, in: Transport ATPases, eds. E. Carafoli and a. Scarpa, New York Academy of Sciences, New York, 1982, p. 457

54. E. Carafoli, in: Calcium Binding proteins: Structure and Function, eds. F.I. Siegel, E. Carafoli, R. Kretsinger, D.H. MacLennan and R.H. Wasserman, Elsevier North-holland, New York, 1980, p. 121

55. S. Silver, in: Microorganisms and Minerals, ed. E.D. Weinberg, Marcel Dekker, Inc., New York, 1977, p. 49

56. R.J.P. Williams, Q. Rev. Chem. Soc., Lond., 24, 331 (1970)

57. R.J.P. Williams, Biochem. Soc. Trans. 1, 826 (1973)

58. R.J.P. Williams, in: Calcium in Biological Systems, ed. C.J. Duncan, Cambridge University Press, Cambridge, 1976, p. 1

59. R.J.P. Williams, in: Calcium Binding Proteins: Structure and Function, eds. F.L. Siegel, E. Carafoli, R. Kretsinger, D.H. MacLennan and R.H. Wasserman, Elsevier NorthHolland, New York, 1980, p. 3

60. R.H. Kretsinger, in: Biomineralization and Biological Metal Accumulation, eds. P. Westbroek and E.W. DeJong, D. Reidel, Dordrecht, 1983, p. 123

61. H.A. Lowenstam and L. Margulis, Biosystems 12, 27, 1980

62. R.H. Kretsinger, in: Calcium Transport in Contraction and Secretion, eds. E. Carafoli, F. Clementi, W. Drabikowski and A. Margreth, Elsevier North-Holland, Amsterdam, 1975, P. 469

63. R.H. Kretsinger and D.J. Nelson, Coord. Chem. Rev. 18, 29 (1976)

64. G.A. Jamieson, Jr., A. Hayes, J.J. Blum and T.C. Vanaman, in: Calcium Binding Proteins: Structure and Function, eds., F.L. Siegel, E. Carafoli, R. Kretsinger, D.H. MacLennan and R.H. Wasserman, Elsevier North-Holland, New York, 1980, p. 165

65. D.M. Watterson, in: The Regulatory Functions of Calcium and the potential Role of Calcium in Mediating Gravitational Responses in Cells and Tissues, ed. S. Roux, NASA, Washington, D.C., 1983, p. 44

66. J.E. Lovelock, in: Biomineralization and Biological Metal Accumulation, eds. P. Westbroek and E.W. DeJong, D. Reidel, Dordrecht, 1983, p. 15

67. E.C. Pollard, in: Gravity and the Organism, eds. S.A. Gordon and M.J. Cohen, University of Chicago Press, Chicago, 1971, p. 25

68. G.W. Nace, Adv. in Space Research 3, \#9, 159 (1983)

69. P. O'B. Monggomery, Jr., J.E. Cox, R.C. Reynolds, J.S. Paul, L. Hayflick, D. Stock, W.W. Shulz, S. Kimzey, R.G. Thirolf, T. Rogers, D. Campbell and J, Murrell, in: BioMedical Results from Skylab, N77-33780, eds. R.S. Johnson and L.F. Dietlein, U.S. Government Printing Office, Washington, D.C., 1977, pp. 221-234

70. E.L. Kordyum and K.M. Sytnik, The Physiologist 26, S-141 (1983) 